\title{
Vascular Calcification and Cardiovascular Outcome in Dialysis Patients: The Role of Gene Polymorphisms
}

\author{
Mario Cozzolino ${ }^{\mathrm{a}}$ Maria Luisa Biondi ${ }^{\mathrm{b}}$ Andrea Galassi ${ }^{\mathrm{a}}$ Daniele Cusi ${ }^{\mathrm{a}, \mathrm{c}}$ \\ Diego Brancaccio ${ }^{c}$ Maurizio Gallieni ${ }^{d}$

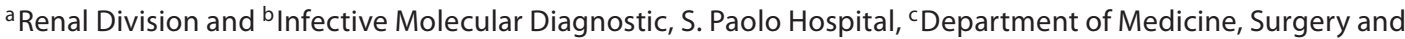 \\ Dentistry, University of Milan School of Medicine, ${ }^{d}$ Renal Division, S. Carlo Hospital, Milan, Italy
}

\section{Key Words}

Hemodialysis · Gene polymorphism • Vascular

calcification · Atherosclerosis

\begin{abstract}
Vascular calcification and accelerated atherosclerosis are major causes of death in hemodialysis (HD) patients. Epigenetic mechanisms of gene regulation may be crucial determinants of cellular behavior in uremic conditions, determining an increased risk of cardiovascular morbidity and mortality. The common polymorphisms on different gene promoters have been related to increased coronary artery calcification and associated with cardiovascular outcome in HD population. In this review, we reported the gene polymorphisms of different proteins as negative prognostic risk factors for allcause mortality in HD patients, independent of traditional risk factors. These data may have important implications for better understanding the pathogenesis of the increased mortality in this population.

Copyright ๑ 2010 S. Karger AG, Basel
\end{abstract}

\section{Introduction}

Cardiovascular (CV) disease (CVD) is the leading cause of mortality in hemodialysis (HD) patients [1]. The very high CV mortality and morbidity rates in this population are only partially explained by the high prevalence of traditional CV risk factors [2], which are classically related to atherosclerosis. The vascular changes observed in chronic kidney disease (CKD) patients consist not only in atherosclerosis, but also in arteriosclerosis associated with both medial and intimal vascular calcification [3]. The degree of arterial stiffening and the extent of calcification are closely related [4], and both of these variables are strong and independent prognostic markers of allcause and CV mortality in patients on $\operatorname{HD}[5,6]$.

In particular, over the last few years, different authors have focalized their own research on investigating the role of genetic polymorphism of different proteins as a negative prognostic risk factor for all-cause mortality in HD patients, independent of traditional risk factors $[7,8]$. These data may have important implications for better understanding the pathogenesis of the increased mortality in this population.

\section{KARGER \\ Fax +4161306 1234 E-Mail karger@karger.ch} www.karger.com
Mario Cozzolino, $\mathrm{MD}, \mathrm{PhD}$

Renal Division, Azienda Ospedale San Paolo

Via A. di Rudinì, 8

IT-20142 Milano (Italy)

Tel. +39 028184 4381, Fax +39 028912 9989, E-Mail mariocozzolino@ hotmail.com 


\section{Vascular Calcification in Dialysis: Which Is the 'Guilty' Protein?}

A mounting number of vascular calcification risk factors are involved in the dialysis population: age, gender, dialysis vintage, inflammation, mineral metabolism abnormalities, and diabetes [9]. In addition to these wellknown features of CKD patients, in the last decade new pathogenetic tools are emerging in the nephrology community to better understand vascular mineralization. In fact, although the calcification process has not been completely elucidated, it is now clear that it does not merely consist in passive deposition of calcium-phosphate crystals; on the contrary, it is a well-organized process, involving cell activity and specific protein synthesis [9].

Accordingly, a large amount of proteins are now certified for their capacity of inducing or inhibiting the process of extra-skeletal calcification, and their potential role as 'protective' or 'noxious' proteins associated with vascular calcification in CKD needs to be clarified. Analyzing those substances recognized as regulatory key factors in inducing vascular calcification in uremic conditions, matrix metalloproteinases (MMPs) have been increasingly implicated in connective tissue remodeling during atherogenesis, contributing to the enlargement and instability of atherosclerotic plaque [10]. Recently, the association of MMP1 and MMP3 polymorphisms with all-cause mortality risk in HD patients has been reported [11]. On the other hand, vascular calcification inhibitors, such as fetuin-A ( $\alpha_{2}$-Heremans-Schmid glycoprotein, AHSG) and the matrix GLA protein (MGP), have been considered in their gene polymorphism modification in HD patients $[12,13]$. In fact, while fetuin-A is considered an important circulating inhibitory protein involved in vascular calcification, MGP is a potent in situ regulator of this dramatic disease.

\section{Role of Atherosclerosis: MMP Gene Polymorphisms}

Recently, we demonstrated that HD patients have a different distribution of MMP1 and MMP3 gene polymorphisms when compared to the normal population [11]. Moreover, HD patients who have combined alterations of gene polymorphisms of the MMP1 and MMP3 appear to have a significantly worse prognosis in terms of mortality [11].

The MMPs are a family of enzymes involved in the biology of extracellular matrix and in atherogenesis. MMP1 and MMP3 participate in the enlargement and instability of atherosclerotic plaque, respectively [14, 15]. The common polymorphisms on MMP1 (2G/2G) and MMP3 (6A/6A) gene promoters have been related to increased coronary artery calcification and to carotid artery stenosis [16].

Accelerated atherosclerosis and CVD have been shown to be associated with the MMP3 gene $5 \mathrm{~A} / 6 \mathrm{~A}$ polymorphism. MMP3 has proteolytic activity on different extracellular matrix proteins $[17,18]$ and can activate other MMPs [18]. Therefore, MMP3 has an important role in vascular and cardiac matrix remodeling [18]. Interestingly, Hu mphries et al. [19] have shown that subjects with the $6 \mathrm{~A} / 6 \mathrm{~A}$ genotype have a higher rate of coronary atherosclerotic lesion growth compared with individuals with the $5 \mathrm{~A} / 5 \mathrm{~A}$ or $5 \mathrm{~A} / 6 \mathrm{~A}$ genotype.

Vascular calcification increases the risk of CV events [9]. MMP3 expression is colocalized with calcium deposition in atherosclerotic lesions [20]. In an autopsy study of men who died of cardiac disease or other causes, Pollanen et al. [21] have found that patients of the $5 \mathrm{~A} / 5 \mathrm{~A}$ or $5 \mathrm{~A} / 6 \mathrm{~A}$ genotype had more calcification in atherosclerotic lesions than subjects of the $6 \mathrm{~A} / 6 \mathrm{~A}$ genotype. Furthermore, individuals of the $6 \mathrm{~A} / 6 \mathrm{~A}$ genotype more likely have advanced carotid atherosclerosis resulting in significant carotid stenosis. In a study of patients with carotid atherosclerosis and controls with no evidence of the disease, Ghilardi et al. [16] showed that the frequency of the $6 \mathrm{~A} / 6 \mathrm{~A}$ genotype was higher in the case group than in the control group, and that among the cases, carriers of the $6 \mathrm{~A} / 6 \mathrm{~A}$ genotype had a higher degree of carotid stenosis. The major constituents of atherosclerotic lesions are matrix proteins (collagen, proteoglycans, elastin, etc.), smooth muscle cells, macrophages, and lipids [22]. Since MMP3 is considered to play an important role in the degradation of matrix proteins in atherosclerotic lesions, and since MMP3 expression in vascular tissues is higher in individuals carrying the $5 \mathrm{~A}$ allele than in individuals of the $6 \mathrm{~A} / 6 \mathrm{~A}$ genotype, a possible explanation for our findings that the $6 \mathrm{~A} / 6 \mathrm{~A}$ genotype is associated with greater mortality risk is that HD patients with the low MMP3 expression $6 \mathrm{~A} / 6 \mathrm{~A}$ genotype are prone to developing atherosclerotic plaques that are rich in matrix proteins and hence relatively large and stable, whereas individuals with the high MMP3 expression $5 \mathrm{~A} / 5 \mathrm{~A}$ or $5 \mathrm{~A} / 6 \mathrm{~A}$ genotype are predisposed to developing atherosclerotic plaques which have less matrix proteins and hence are smaller but prone to rupture.

Furthermore, in a recent study, Lehrke et al. [23] observed 260 patients with typical or atypical chest pain who underwent dual-source CT-coronary angiography 


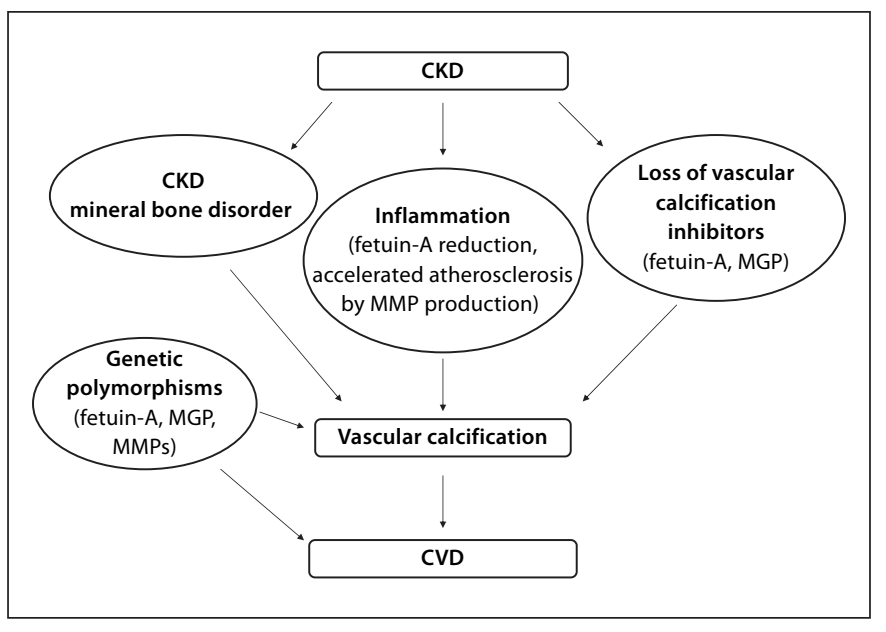

Fig. 1. Evolution of understanding of pathogenesis of vascular calcification in CKD. Possible mechanisms involved in the physiopathology of vascular calcification in CKD. CKD-mineral bone disorder, inflammation, and loss of calcification-inhibitory proteins are three of the major factors investigated in this process. In addition, genetic polymorphisms of proteins involved in the pathogenesis of vascular calcification and CV mortality, such as fetuin-A, MGP, and MMPs 1 and 3, represent a new aspect to investigate in $\mathrm{CKD}$ patients.

for exclusion of coronary artery stenosis. In a multivariable regression analysis, serum MMP1 levels were associated with calcified plaque burden, while no association was found between serum MMP9 levels and total plaque burden or plaque morphology.

\section{Role of Inflammation: Fetuin-A Gene Polymorphisms}

Fetuin-A, also known as AHSG, is an abundant serum protein of the cystatin superfamily of cysteine protease inhibitors synthesized by the liver and found throughout the body in the extracellular space. Even if AHSG physiological roles are still under investigation, numerous reports have supported evidence that fetuin-A is a multifunctional protein. It is a negative, acute-phase $62-\mathrm{kDa}$ glycoprotein that is able to prevent ectopic calcification [24].

A considerable body of evidence indicates that deficiency of fetuin-A may contribute to vascular calcification in CKD: massive ectopic calcification occurs in fetuin-A knockout mice receiving a diet with a high content of calcium and vitamin D [24]; fetuin-A serum levels are significantly lower in CKD patients with calciphylaxis compared to other CKD subjects [25]; the inability of human uremic plasma to inhibit the precipitation of calcium and phosphorus is corrected by the addition of fetuin-A, which accounts for more than $50 \%$ of the precipitation inhibitory effect of serum [24].

Furthermore, HD patients are affected by a chronic inflammatory state, represented by lower levels of fetuinA. Chronic inflammation is also associated with a higher risk of CVD in HD. Recently, Ketteler et al. [26] have shown that in HD patients fetuin-A is an independent predictor of all-cause and CV mortality. Moreover, we have recently shown the independent and significant association between reduced serum fetuin-A levels and multi-site vascular calcification in HD patients, investigated with an ultrasound technique [27].

Indeed, in a recent study, Stenvinkel et al. [28] demonstrated that CKD patients with elevated inflammatory markers and with AHSG 256Ser allele had lower serum fetuin-A levels and higher all-cause and CV mortality rates.

We performed a similar study in Italian HD patients to assess the relationship between serum fetuin-A levels and its gene (AHSG) polymorphisms [12]. This study suggests that this group of Italian HD patients have a similar distribution of AHSG gene polymorphism as compared to the normal population. In contrast to previous reports [28], this study suggests that CKD patients that receive $\mathrm{HD}$ treatment have a reduction in serum fetuin-A levels that is not associated with alteration on the distribution of AHSG T256S polymorphisms. Consequently, altered polymorphism of the fetuin-A gene does not appear to be a negative prognostic factor for the progression to CVD in this population.

Recently, different authors have investigated the distribution of AHSG gene polymorphism in dialysis patients [28], in subjects with subclinical atherosclerosis [29], and in Alzheimer's disease patients [30]. Stenvinkel et al. [28] recently reported significantly lower serum fetuin-A levels in Swedish dialysis patients with the AHSG T256S allele, in association with an increased CV and all-cause mortality rates. Indeed, other recent studies demonstrated that serum fetuin-A levels are linked to inflammation in early stages of renal insufficiency [31], in dialysis population [27], and in renal transplant patients [32] independently by AHSG gene polymorphism distribution.

Probably, the reason that some recent clinical results are different from our findings may be explained by the differences in races. It should be borne in mind that numerous factors contribute towards the marked arterial calcifi- 
cation observed in CKD patients: all the 'classic' risk factors for atherosclerosis plus 'uremia-associated' risk factors, such as duration of dialysis, uremic toxins, inflammation, increased serum levels of phosphate, calcium-phosphate product and PTH. However, the importance of fetuin-A in arterial calcification has been demonstrated as an important protective factor against arterial calcification, even if its definitive role remains to be elucidated.

\section{Role of in situ Vascular Calcification Inhibition: MGP Gene Polymorphisms}

MGP is a vitamin K-dependent extracellular matrix protein with a molecular weight of $10 \mathrm{kDa}$. MGP is present in cartilage, bone matrix and the arterial wall, where it inhibits the deposition of calcium phosphate. MGP knockout mice are normal at birth, but rapidly develop severe and arterial calcifications and almost invariably die of rupture of the aorta within 6-8 weeks [33]. Moreover, MGP is highly expressed in human atheromatous plaques [34].

The most common MGP polymorphisms identified are MGP-7 and MGP-138 isoforms [35]. Both of these polymorphisms have an important impact on in vitro promoter activity when they are transfected into vascular smooth muscle cells. In particular, the MGP-138C variant is associated with higher MGP serum levels (+30\%) [36]. In clinical studies, MGP-7 AA homozygotes have been shown to have a significantly higher risk of myocardial infarction in a low-risk male population (OR 3.82) and to exhibit femoral artery calcification in the presence of femoral atherosclerotic plaque more frequently than subjects with other genotypes $(p<0.025)$ [35]. In a recent clinical study in 204 patients with end-stage renal disease (ESRD), MGP-7 AA homozygosity was found to be associated with a higher level of left ventricular hypertrophy $(\mathrm{p}<0.05)$ and accelerated progress of atherosclerosis in 1 year, based on carotid artery ultrasound assessments, than other genotypes [36]; MGP-138CC genotype was associated with an increase in $\mathrm{CV}$ and total mortality in ESRD patients [37].

Recently, we investigated the distribution of MGP-7 and MGP-138 genotypes in CKD and HD patients, followed up for 12 months, to evaluate the relationship between genotype and CV mortality [13]. We found that CKD and HD patients have a different distribution of MGP gene polymorphism when compared to the normal population. Consequently, altered polymorphism of the MGP gene appears to be a negative prognostic factor in terms of CV mortality in HD patients. Wang et al. [38] have reported significantly more severe left ventricular hypertrophy and an accelerated progress of atherosclerosis, defined as the change in calculated carotid intima media area, in 1 year in 58 ESRD patients. Thus, our findings contribute towards the body of evidence suggesting that $-7 \mathrm{~A}$ allele carriers with $\mathrm{CKD}$ have an increased risk of calcification and related CV events. The findings related to -138 polymorphisms are consistent with previous in vitro data suggesting the $-138 \mathrm{~T}$ variant is 4 -fold less active than the $-138 \mathrm{C}$ variant [37].

\section{Conclusions}

'Classical' CV risk factors are common in dialysis patients, but they cannot explain alone the dramatic high prevalence of CV morbidity and mortality. The role of various 'non-classical' CV risk factors, such as vascular calcification, inflammation, and oxidative stress, is under investigation. In addition, genetic factors such as gene polymorphisms of specific proteins may significantly contribute to the prevalence of vascular calcification in this group of HD patients.

During the last decade, there has been a great interest in vascular calcification as a nontraditional risk factor for CVD in CKD and HD patients. To better elucidate the respective roles of gene polymorphisms of proteins involved in production (such as MMP1 and MMP3) or inhibition (such as fetuin-A and MGP) of vascular calcification, prospective studies are warranted. This will help the nephrology community to identify the role of gene polymorphism in determining $\mathrm{CV}$ calcification in HD patients in the attempt to improve our understanding of the pathogenesis of increased risk of ectopic calcification and $\mathrm{CV}$ events in patients with renal failure.

\section{Acknowledgements}

This research was supported in part by an investigator supported trial grant from Shire Pharmaceuticals (M.C., D.B.) and in part by Ingenious Hypercare LSHM-CT-2006-037093 (D.C.), by HYPERGENES grant HEALTH-F4-2007-201550 (D.C.). 


\section{References}

1 Foley RN, Parfrey PS: Clinical epidemiology of cardiovascular disease in chronic renal disease. Am J Kidney Dis 1998;32(suppl 3): S112-S119.

$\checkmark 2$ Zoccali C, Tripepi G, Mallamaci F: Predictors of cardiovascular death in ESRD. Semin Nephrol 2005;25:358-362.

- 3 Longenecker JC, Coresh J, Powe NR, et al: Traditional cardiovascular disease risk factors in dialysis patients compared with the general population: the CHOICE study. J Am Soc Nephrol 2002;13:1918-1927.

-4 London GM: Cardiovascular calcifications in uremic patients: clinical impact on cardiovascular function. J Am Soc Nephrol 2003;14:S305-S309.

5 Cozzolino M, Brancaccio D, Gallieni M, Slatopolsky E: Pathogenesis of vascular calcification in chronic kidney disease. Kidney Int 2005;68:429-436.

-6 Cozzolino M, Mazzaferro S, Pugliese F, Brancaccio D: Vascular calcification and uremia: what do we know? Am J Nephrol 2008;28:339-346.

7 Stenvinkel, Ekstrom TJ: Epigenetics: a helpful tool to better understand processes in clinical nephrology? Nephrol Dial Transplant 2008;23:1493-1496.

-8 Nordfors L, Lindholm B, Stenvinkel P: Endstage renal disease: not an equal opportunity disease: the role of genetic polymorphisms. J Int Med 2005;258:1-12.

\9 Cozzolino M, Dusso AS, Slatopolsky E: Role of calcium-phosphate product and bone-associated proteins on vascular calcification in renal failure. J Am Soc Nephrol 2001;12: 2511-2516.

10 Dollery CM, McEwan JR, Henney AM: Matrix metalloproteinases and cardiovascular disease. Circ Res 1995;77:863-878.

-11 Cozzolino M, Biondi ML, Galassi A, et al: Matrix metalloproteinase-1 and matrix metalloproteinase-3 gene promoter polymorphisms are associated with mortality in haemodialysis patients. Nephrol Dial Transplant 2009;24:2207-2212.

12 Cozzolino M, Biondi ML, Galassi A, et al: Gene polymorphisms and serum alpha-2Heremans-Schmid levels in Italian haemodialysis patients. Am J Nephrol 2007;27:639642.

13 Brancaccio D, Biondi ML, Gallieni M, et al: Matrix GLA protein gene polymorphisms: clinical correlates and cardiovascular mortality in chronic kidney disease patients. Am J Nephrol 2005;25:548-552.

-14 Nikkari ST, O’Brian KD, Ferguson M, et al: Interstitial collagenase (MMP-1) expression in human carotid atherosclerosis. Circulation 1995;92:1393-1398.
15 Ye S, Eriksson P, Hamsten A, et al: Progression of coronary atherosclerosis is associated with a common genetic variant of the human stromelysin-1 promoter which results in reduced gene expression. J Biol Chem 1996; 271:13055-13060.

16 Ghilardi G, Biondi ML, DeMonti M, et al: Matrix metalloproteinase-1 and matrix metalloproteinase- 3 gene promoter polymorphisms are associated with carotid artery stenosis. Stroke 2002;33:2408-2412.

$\checkmark 17$ Newby AC, Johnson JL: Genetic strategies to elucidate the roles of matrix metalloproteinases in atherosclerotic plaque growth and stability. Circ Res 2005;97:958-960.

18 Abilleira S, Bevan S, Markus HS: The role of genetic variants of matrix metalloproteinases in coronary and carotid atherosclerosis. J Med Genet 2006;43:897-901.

19 Humphries SE, Luong LA, Talmud PJ, et al: The $5 \mathrm{~A} / 6 \mathrm{~A}$ polymorphism in the promoter of the stromelysin-1 (MMP-3) gene predicts progression of angiographically determined coronary artery disease in men in the LOCAT gemfibrozil study. Lopid Coronary Angiography Trial. Atherosclerosis 1998;139: 49-56.

20 Libby P: Molecular bases of the acute coronary syndromes. Circulation 1995;91:28442850.

21 Pollanen PJ, Lehtimaki T, Ilveskoski E, et al: Coronary artery calcification is related to functional polymorphism of matrix metalloproteinase 3. The Helsinki Sudden Death Study. Atherosclerosis 2002;164:329-335.

22 Gnasso A, Motti C, Irace C, et al: Genetic variation in human stromelysin gene promoter and common carotid geometry in healthy male subjects. Arterioscler Thromb Vasc Biol 2000;20:1600-1605.

23 Lehrke M, Greif M, Broedl UC, et al: MMP-1 serum levels predict coronary atherosclerosis in humans. Cardiovasc Diabet 2009;8: 50.

24 Schinke T, Amendt C, Trindl A, et al: The serum protein $\alpha_{2}$-HS glycoprotein/fetuin inhibits apatite formation in vitro and in mineralizing calvaria cells. J Biol Chem 1996; 271:20789-20796.

25 Schäfer C, Heiss A, Schwarz A, et al: The serum protein $\alpha_{2}$ Heremans-Schmid glycoprotein/fetuin $\mathrm{A}$ is a systemically acting inhibitor of ectopic calcification. J Clin Invest 2003;112:357-366

26 Ketteler M, Bongartz P, Westenfeld R, et al: Association of low fetuin-A (AHSG) concentrations in serum with cardiovascular mortality in patients on dialysis: a cross-sectional study. Lancet 2003;361:827-833.
27 Cozzolino M, Galassi A, Biondi ML, et al: Serum fetuin-A levels link inflammation and cardiovascular calcification in haemodialysis patients. Am J Nephrol 2006;26:423429.

28 Stenvinkel P, Wang K, Qureshi AR, et al: Low fetuin-A levels are associated with cardiovascular death: impact of variations in the gene encoding fetuin. Kidney Int 2005;67: 2383-2392.

29 Lehtinen AB, Burdon KP, Lewis JP, et al: Association of alpha2-Heremans-Schmid glycoprotein polymorphisms with subclinical atherosclerosis. J Clin Endocrinol Metab 2007;92:345-352.

30 Geroldi D, Minoretti P, Bianchi M, et al: Genetic association of alpha2-HeremansSchmid glycoprotein polymorphism with late-onset Alzheimer's disease in Italians. Neurosci Lett 2005;386:176-178.

31 Russo D, Corrao S, Mirando I, et al: Progression of coronary artery calcification in predialysis patients. Am J Nephrol 2007;27:152158.

32 Mazzaferro S, Pasquali M, Pugliese F, et al: Serum levels of calcification inhibition proteins and coronary artery calcium score: comparison between transplantation and dialysis. Am J Nephrol 2007;27:75-83.

- 33 Luo G, Ducy P, McKee MD, et al: Spontaneous calcification of arteries and cartilage in mice lacking matrix GLA protein. Nature 1997;386:78-81.

34 Shanahan CM, Cary NR, Metcalfe LC, Weissberg PL: High expression of genes for calcification-regulating proteins in human atherosclerotic plaques. Clin Invest 1994;93: 2393-2402.

-35 Herrmann SM, Whatling C, Brand E, et al: Polymorphisms of the human matrix GLA protein (MGP) gene, vascular calcification and myocardial infarction. Arterioscler Thromb Vasc Biol 2000;20:2386-2393.

-36 Farzaneh-Far A, Davies JD, Braam LA, et al: A polymorphism of the human matrix $\gamma$ carboxyglutamic acid protein promoter alters binding of an activating protein-1 complex and is associated with altered transcription and serum levels. J Biol Chem 2001; 276:32466-32473.

37 Wang K, Honda H, Qureshi AR, et al: Association between the matrix GLA protein-7 polymorphism and carotid intima-media area and left ventricular hypertrophy in endstage renal disease patients. ERA-EDTA XLI Congr, May 2004, Lisbon.

38 Wang K, Honda H, Qureshi AR, et al: The matrix GLA protein-138 genotype is associated with clinical outcome in end-stage renal disease patients. ERA-EDTA XLI Congr, May 2004, Lisbon. 